\title{
Maturity and Well-Being: Consistent Associations Across Samples and Measures
}

\author{
Stephen Reysen, $\mathrm{PhD}^{1}$, Courtney N. Plante, $\mathrm{PhD}^{2}$, Truong Quang Lam, $\mathrm{PhD}^{3}$, Shanmukh V. Kamble, $\mathrm{PhD}^{4}$, \\ Iva Katzarska-Miller, PhD ${ }^{5}$, Natalia Assis, MBA' , Grace Packard, BS ${ }^{6}$, Eduardo Gregolin Moretti, BS
}

\begin{abstract}
Introduction: Researchers have noted an association between maturity and well-being. However, this body of research uses different measures and conceptualizations of maturity (e.g., ego development, psychosocial maturity) and often only a few indicators of well-being. In the present research, we examined associations between a single self-rated measure of maturity and a variety of different indicators of well-being. Furthermore, we examined this association across a variety of samples. We hypothesized that maturity would show a positive relationship with measures related to well-being.
\end{abstract}

Methods: Samples of college students (Studies 1, 3, 4), Star Wars fans (Study 2), and individuals in the U.S., Canada, Brazil, Vietnam, and India (Study 5) completed a short measure of maturity and measures related to well-being.

Results: Across the studies, self-rated maturity was consistently positively correlated with various indicators of well-being (e.g., psychological, physical) and related constructs (e.g., self-compassion, empathy).

Conclusion: The results highlight the association between maturity and well-being. Furthermore, the results address the fragmented nature of this association in the literature by showing consistent relationships with a variety of well-being indicators with a single measure of maturity. Assessments of maturity may be beneficial in hiring decisions and student evaluation in the healthcare profession.
DOI: 10.18297/jwellness/vol2/iss2/10

Received Date: June 24, 2020 Accepted Date: Nov 11, 2020 Publication Date: Dec 9, 2020 Website: https://ir.library.louisville.edu/ jwellness/

Recommended Citation: Reysen, Stephen; Plante, Courtney N.; Lam, Truong Quang; Kamble, Shanmukh V.; Katzarska-Miller, Iva; Assis, Natalia; Packard, Grace; Moretti, Eduardo Gregolin (2020) "Maturity and Well-Being: Consistent Associations Across Samples and Measures" Journal of Wellness: Vol. 2 : Iss. 2, Article 10.

Affiliations: 'Texas A\&M University-Commerce, ${ }^{2}$ Bishop's University, ${ }^{3}$ University of Social Sciences and Humanities Vietnam National University, ${ }^{4}$ Karnatak University ${ }^{5}$ Transylvania University ${ }^{6} \mathrm{G}$ Goorgiversity, Transylvania University, ${ }^{6} \mathrm{Georgia}$ State Un versity, 'Institu
do Stress

\section{INTRODUCTION}

Among the earliest questions posed by philosophers around the world was how to live a fruitful and ultimately satisfying life. Millennia later, psychologists find themselves tackling the same question, focusing their answers primarily on the psychological precursors of well-being [1]. Despite an abundance of different psychological models of well-being, it is often construed as consisting of two broad dimensions [2-4]. The first dimension represents subjective well-being: A person's self-reported feelings of happiness, satisfaction with life, optimism, and self-esteem. The second dimension represents growth and evidence of one's well-being, including self-actualization, self-improvement, positive relations with others, and evidence of having a sense of purpose or direction. Various researchers have used different terms to describe these two dimensions, including subjective and psychological well-being [4], subjective well-being and growth [2], and hedonic and eudaimonic well-being [1]. Despite these differences in terminology, however, they all construe well-being as multifaceted and aim to understand the precursors to well-being. In the present research we aim to contribute to this ever-increasing list of precursors to well-being by examining a relatively under-studied, but conceptually relevant variable, perceived maturity, and its association with a well-being indicators.

\section{Maturity and Well-Being}

There is ample evidence to suggest that maturity, construed in a variety of ways [5-10], is generally related to various aspects of well-being. Psychosocial maturity is related to

${ }^{*}$ Correspondence To: Stephen Reyse

Email: Stephen.Reysen@tamuc.edu greater self-esteem and less relationship anxiety in U.S. high school students $[7,11]$, less antisocial behavior in juvenile offenders [12], and greater self-esteem and lower depression in Canadian college students [13]. Adolescent boys and girls attending high school while working part-time showed a positive correlation between ego identity and self-esteem, and a negative relationship between ego identity, a measure of maturity, and psychological stress [14]. Identity resolution is positively associated with greater psychological health in a sample of Canadians [9]. Multifaceted measures of maturity (e.g., emotional maturity, character maturity) have also been associated with lower depression in a sample of Canadians [15], subjective well-being with U.S. adults [16], less loneliness in a sample of adolescents in Portugal [17], greater empathy in a sample of U.S. college students [18], psychological and subjective well-being in a sample of Italian late adolescents [19], and general well-being in a sample of adolescents in Kerala, India [20]. Across numerous measures of well-being and maturity and across culturally distinct samples, maturity is consistently associated with well-being.

Not all studies agree with these findings, however. Other studies have yielded mixed results. For example, using a measure of ego development (i.e., maturity), Bauer and McAdams [21] examined correlations between maturity, satisfaction with life, and Ryff and Keyes' [22] measure of well-being in samples of U.S. college students and adults. Greater ego development was related to well-being, but not life satisfaction among students, and ego development was not significantly related to

Copyright: $\odot 2020$ The author(s). This is an open access article distributed under the terms of the Creative Commons Attribution 4.0 International License (CC BY 4.0), which permits (n) distribution, and reproduction in any medium, provided the original author and source are credited. 
either measure in a sample of adults. McCrae and Costa [23] likewise surveyed U.S. adult males and assessed maturity and positive and negative affect. The results found nonsignificant associations between maturity and well-being.

\section{Maturity in Healthcare Profession}

Within the healthcare literature, the concept of maturity is often discussed but rarely measured. Maturity is suggested as a component of medical professionalism [24-27], general physician competencies [28], and related to aspects of one's work such as critical thinking [29], compassion [30], and collaboration on healthcare teams [31-33]. Other researchers have suggested that maturity is related to better patient communication [34], clinical judgment [35], and information delivery to the family of critically ill patients [36]. Given the importance of maturity, the construct could be vital for student selection and hiring decisions [37-40]. Maturity may be related to better healthcare professionals' well-being including satisfaction with life [41], coping with stressors [42], favorable transition to clinical environment [43], and reduced burnout $[44,45]$. However, maturity in much of this research is mentioned but not assessed by the researchers.

Together, the results suggest that maturity and well-being, two constructs that have been assessed in a myriad of ways, are often but not always positively associated. In the present research we examine the association between maturity and well-being using a simplified and straightforward assessment of maturity and various measures of well-being. Such a study will aid in examining the association between maturity and well-being beyond the patchwork of research into maturity's association with one particular dimension of well-being. In other words, we conducted a series of studies with a single measure of maturity and a variety of indicators of well-being reflecting the two larger dimensions of well-being (i.e., subjective and psychological well-being) and measures often associated with well-being (e.g., social support, empathy). Furthermore, we examined these relationships across different samples.

\section{Overview of Present Studies}

The purpose of the present research was to examine associations between self-rated maturity and indicators of well-being. As noted, there is evidence to suggest an association, yet the variety of measures used to assess each of the constructs leaves the literature with disparate results. We tested the association between maturity and indicators of well-being using a short, two-item self-report measure of maturity. In Study 1 we sought to determine the association between maturity and well-being in a large sample of undergraduate students. In Study 2 we examined the association in a more diverse sample of participants (Star Wars fans) and included constructs often related to well-being (e.g., empathy, self-awareness). In Study 3 we examined the association with additional measures related to well-being (e.g., loneliness, purpose in life). In Study 4 we examined the association with a more objective measure of physical well-being (i.e., body mass index) and validated single-item scales of dimensions of well-being. Lastly, in Study 5 we examined the associations between the single-item measures and maturity in samples from five countries (U.S., Canada, Brazil, Vietnam, and India). Across these samples and measures we predicted that perceived maturity would be positively associated with well-being, regardless of how well-being was operationalized. All correlational analyses were conducted with SPSS 19.

\section{STUDY 1}

The purpose of Study 1 was to assess the association between maturity and well-being in a large sample of college students.

\section{Participants and Procedure}

Participants included undergraduate students at Iowa State University participating for course credit (see Table 1 for participant characteristics; approved by Iowa State University IRB \#16-394). As part of a larger study regarding fan interests, participants completed measures regarding self-rated maturity and well-being. All measures used a 7-point Likert-type scale, from 1 = strongly disagree to $7=$ strongly agree.

Table 1: Sample Characteristics

\begin{tabular}{cccc}
\hline Study & $\boldsymbol{N}$ & \% Female & $\boldsymbol{M}_{\text {age }}$ (SD) \\
\hline Study 1 & 790 & $56.8 \%$ & $19.26(1.96)$ \\
Study 2 & 1925 & $30.3 \%$ & $24.05(6.94)$ \\
Study 3 & 195 & $75.4 \%$ & $22.44(7.05)$ \\
Study 4 & 211 & $76.3 \%$ & $21.15(5.02)$ \\
Study 5: US & 202 & $80.2 \%$ & $21.77(6.52)$ \\
Study 5: CA & 149 & $73.8 \%$ & $21.17(4.45)$ \\
Study 5: BR & 119 & $61.3 \%$ & $30.87(9.12)$ \\
Study 5: VN & 147 & $70.1 \%$ & $18.54(0.98)$ \\
Study 5: IN & 192 & $76.6 \%$ & $21.59(1.60)$ \\
\hline
\end{tabular}

US = United States of America, CA = Canada, BR = Brazil, VN = Vietnam, IN = India

\section{Measures}

An existing two-item measure ("I am a mature person" and "Other people would describe me as a mature person" [10]) was used to assess perceived maturity $(\alpha=.78 ; M=5.65$, $\mathrm{SD}=1.12)$. To assess well-being, we adapted a 24 -item BBC well-being measure from prior research [46] that measures three dimensions of well-being: physical health ("I am satisfied with my physical health"), psychological well-being ("I feel that I am able to enjoy life"), and relationship satisfaction ("I am satisfied with my friendships and personal relationships"). Both the maturity [10] and well-being [46] measures have shown good reliability and validity in prior research.

\section{Results}

To examine the associations between maturity and dimensions of well-being, we conducted zero-order correlations. As shown in Table 2, self-rated maturity was positively correlated with physical well-being, subjective well-being, and positive relationships with others (see Table 2 on next page for correlations, means and standard deviation, and scale alphas).

\section{Discussion}

The results provide initial evidence of an association between maturity and three dimensions of well-being, albeit at a single U.S. university. Additionally, this study only analyzed the association with one measure of well-being. To explore the robustness of these associations, we conducted a second study using a more diverse sample (Star Wars fans) and a greater variety of indicators and well-being related measures. 
Table 2: Correlations with Maturity, Scale Means (Standard Deviation), and Alphas, Studies 1, 2, 3, \& 4

\begin{tabular}{|c|c|c|c|c|}
\hline Variable & $r$ & No. Items & Mean (SD) & $a$ \\
\hline \multicolumn{5}{|l|}{ Study 1} \\
\hline BBC Physical & $.16^{* *}$ & 7 & $5.23(1.02)$ & .82 \\
\hline BBC Well-being & $.24^{* *}$ & 12 & $5.32(0.94)$ & .89 \\
\hline BBC Relationships & $.19^{* *}$ & 5 & $5.39(1.08)$ & .79 \\
\hline \multicolumn{5}{|l|}{ Study 2} \\
\hline Over-Identification & $.10^{* *}$ & 2 & $3.03(1.54)$ & .79 \\
\hline Self-Kindness & $.21^{* *}$ & 2 & $3.88(1.30)$ & .58 \\
\hline Mindfulness & $.27^{* *}$ & 2 & $4.79(1.39)$ & .73 \\
\hline Isolation & $.09^{* *}$ & 2 & $3.13(1.55)$ & .66 \\
\hline Common Humanity & $.18^{* *}$ & 2 & $4.22(1.57)$ & .72 \\
\hline Self-Judgment & $.10^{* *}$ & 2 & $3.35(1.51)$ & .76 \\
\hline Empathy & $.11 * *$ & 5 & $5.01(1.17)$ & .81 \\
\hline Private Self-Awareness & $.23^{* *}$ & 3 & $5.42(1.21)$ & .81 \\
\hline Stress & $-.13^{* *}$ & 4 & $3.97(1.46)$ & .81 \\
\hline Satisfaction with Life & $.25^{* *}$ & 1 & $4.55(1.67)$ & -- \\
\hline Self-Esteem & $.27^{* *}$ & 1 & $4.02(1.76)$ & -- \\
\hline \multicolumn{5}{|l|}{ Study 3} \\
\hline Autonomy & $.24^{* *}$ & 7 & $4.03(0.90)$ & .80 \\
\hline Environmental Mastery & $.30 * *$ & 7 & $3.87(0.82)$ & .75 \\
\hline Personal Growth & $.23^{* *}$ & 7 & $4.46(0.97)$ & .83 \\
\hline Positive Relations & $.35^{* *}$ & 7 & $4.24(0.89)$ & .79 \\
\hline Purpose in Life & $.27^{* *}$ & 7 & $4.33(0.97)$ & .83 \\
\hline Self-Acceptance & $.29^{* *}$ & 7 & $4.02(0.98)$ & .82 \\
\hline Optimism & $.25^{* *}$ & 8 & $4.34(1.12)$ & .83 \\
\hline Emotional Support & $.34^{* *}$ & 8 & $5.60(1.38)$ & .97 \\
\hline Instrumental Support & $.27^{* *}$ & 8 & $5.23(1.66)$ & .97 \\
\hline Loneliness & $-.26^{* *}$ & 10 & $3.46(1.63)$ & .96 \\
\hline Satisfaction with Life & $.22^{* *}$ & 5 & $4.47(1.40)$ & .88 \\
\hline Self-Esteem & $.36^{* *}$ & 6 & $4.81(1.25)$ & .84 \\
\hline \multicolumn{5}{|l|}{ Study 4} \\
\hline SI Physical & $.28^{* *}$ & 1 & $4.77(1.46)$ & -- \\
\hline SI Autonomy & $.42^{* *}$ & 1 & $4.85(1.48)$ & -- \\
\hline SI Mastery & $.52^{* *}$ & 1 & $4.96(1.42)$ & -- \\
\hline SI Growth & $.45^{* *}$ & 1 & $5.33(1.49)$ & -- \\
\hline SI Relations & $.51^{* *}$ & 1 & $5.37(1.46)$ & -- \\
\hline SI Purpose in Life & $.50^{* *}$ & 1 & $5.29(1.59)$ & -- \\
\hline SI Self-Acceptance & $.45^{* *}$ & 1 & $4.85(1.70)$ & -- \\
\hline BBC Physical & $.42^{* *}$ & 5 & $4.64(1.31)$ & .89 \\
\hline Body Mass Index & $-.27^{* *}$ & 1 & $25.98(9.53)$ & -- \\
\hline Autonomy & $.31^{* *}$ & 7 & $3.96(0.85)$ & .73 \\
\hline Mastery & $.45^{* *}$ & 7 & $3.81(0.85)$ & .74 \\
\hline Growth & $.19^{* *}$ & 7 & $4.42(0.97)$ & .82 \\
\hline Relations & $.40^{* *}$ & 7 & $4.13(0.91)$ & .76 \\
\hline Purpose in Life & $.32^{* *}$ & 7 & $4.17(0.98)$ & .82 \\
\hline Self-Acceptance & $.39 * *$ & 7 & $3.92(0.96)$ & .79 \\
\hline
\end{tabular}

Note. ${ }^{* *} p<.01, \mathrm{SI}=$ single item. A Cronbach's alpha above .70 suggests good reliability [65]. For more information regarding calculation and interpretation of Pearson product-moment correlation see $[66,67]$.

\section{STUDY 2}

The purpose of Study 2 was to examine the associations between perceived maturity and indicators of well-being in a broader sample of participants than was used in Study 1-Star Wars fans. Although a sample of convenience, the diversity of participants could allow generalization beyond college students. Additionally, we included measures that, while not directly assessing well-being, have been shown to be closely tied to well-being, including the constructs of self-compassion [47], empathy [48], and self-awareness [49]. Similar to Study 1, we predicted positive associations between maturity and these well-being related measures.

\section{Participants and Procedure}

Participants included self-identified Star Wars fans recruited from websites related to the fandom (see Table 1 for participant characteristics; approved by Texas A\&M
University-Commerce IRB \#1722). The majority indicated being from the U.S. (61.7\%). As part of a larger study regarding the Star Wars fandom, participants completed measures regarding self-compassion, empathy, self-awareness, stress, satisfaction with life, and self-esteem. Unless noted otherwise, measures used a 7-point Likert-type scale, from $1=$ strongly disagree to $7=$ strongly agree.

\section{Measures \\ Maturity}

Maturity was assessed with the same measure as in Study 1 $(\alpha=.79 ; \mathrm{M}=5.27, \mathrm{SD}=1.21)$.

\section{Self-compassion}

We adopted a short form scale of self-compassion [50] that assesses dimensions of over-identification (e.g., "When I'm feeling down I tend to obsess and fixate on everything that's wrong;" reversed), self-kindness (e.g., "When I'm going through a very hard time, I give myself the caring and tenderness I need"), mindfulness (e.g., "When something upsets me I try to keep my emotions in balance"), isolation (e.g., "When I fail at something that's important to me, I tend to feel alone in my failure;" reversed), common humanity (e.g., "I try to see my failings as part of the human condition"), and self-judgment (e.g., "I'm disapproving and judgmental about my own flaws and inadequacies;" reversed). The items were rated on a 7 -point scale, from $1=$ almost never to $7=$ almost always. Research [50] showed the measure is reliable and highly correlated with a longer form of the measure.

\section{Empathy}

We adopted five items (e.g., "I often have tender, concerned feelings for people less fortunate than me") from prior research [51] to assess empathy. Prior research [51] showed a longer version of this measure to be reliable and valid.

Self-awareness. We adapted three items (e.g., "Typically, I am conscious of my inner feelings") from prior research [52] to assess private self-awareness. Reliability and validity is shown in prior research [52].

\section{Stress}

We adopted four items (e.g., "Recently I found it difficult to relax") from prior research [53] to assess participants' degree of stress. Items were rated on a 7-point scale from $1=$ not at all to $7=$ most of the time. Prior research [53] showed the longer version of this measure to be reliable and correlated with relevant measures (e.g., anxiety).

\section{Satisfaction with life}

We adapted a single-item measure of satisfaction with life ("I am satisfied with my life") from prior research $[54,55]$. Single-item measures of life satisfaction have been shown to be reliable [54], and the measure is related to variables similar to other indicators of well-being [55].

Self-esteem. We adopted a single-item ("I have high self-esteem") from prior research [56] to assess participants' degree of self-esteem. Prior research [56] shows the measure is reliable and showed a similar correlation pattern as a longer measure of self-esteem.

\section{Results}

As shown in Table 2, self-rated maturity was significantly positively related to self-compassion dimensions, empathy, self-awareness, and single-item measures of satisfaction with life and self-esteem. Additionally, maturity was negatively associated with stress. 


\section{Discussion}

Thus, the results from a broader, more diverse sample replicated the relationship between maturity and indicators of well-being shown in Study 1. To bolster the argument that maturity is associated with indicators of well-being, we conducted a third study using different indicators of well-being. Furthermore, because we used single-item measures of satisfaction with life and self-esteem in Study 2, we included longer measures of these constructs in Study 3.

\section{STUDY 3}

The purpose of Study 3 was to examine the associations between maturity and well-being in different university sample and different measures of well-being.

\section{Participants and Procedure}

Participants included undergraduate students at Texas A\&M University-Commerce participating for course or extra credit (see Table 1 for participant characteristics; approved by Texas A\&M University-Commerce IRB \#1472). Participants completed measures related to well-being and maturity in a randomized order. Unless noted otherwise, measures used a 7-point Likert-type scale, from $1=$ strongly disagree to $7=$ strongly agree.

\section{Measures \\ Maturity}

Maturity was assessed with the same measure utilized in Study $1(\alpha=.87 ; M=5.99, \mathrm{SD}=1.08)$.

\section{Well-being}

We included a 42-item measure of well-being [4, 22], that tapped into six dimensions of well-being: autonomy (e.g., "My decisions are not usually influenced by what everyone else is doing"), environmental mastery (e.g., "I am quite good at managing the many responsibilities of my daily life"), personal growth (e.g., "I have the sense that I have developed a lot as a person over time"), positive relations with others (e.g., "Most people see me as loving and affectionate"), purpose in life (e.g., "I enjoy making plans for the future and working to make them a reality"), and self-acceptance (e.g., "In general, I feel confident and positive about myself"). Items were rated on a 6 -point scale, from $1=$ strongly disagree to $6=$ strongly agree. Prior research $[4,22]$ has shown reliability and validity. Optimism. We adopted an 8-item (e.g., "I'm always optimistic about my future") measure of perceived optimism [57]. Reliability and validity were shown in prior research [57].

\section{Social support}

A 16-item measure of social support [58] was included to assess emotional (e.g., "I have someone to talk with when I have a bad day") and instrumental (e.g., "I have someone to help me if I'm sick in bed") support. Prior research [58] shows the measure is valid and reliable.

\section{Loneliness}

We included a 10-item (e.g., "How often do you feel isolated from others?") measure of loneliness [59]. Items were rated on a 7 -point scale, from $1=$ never to $7=$ always. Prior research [59] showed the measure is reliable and related to relevant measures (e.g., social support, burnout, and other loneliness measures).

\section{Satisfaction with life}

We adopted a 5-item (e.g., "In most ways my life is close to my ideal") measure of satisfaction with life from prior research [60]. Reliability and validity were shown in prior research [60]. Self-esteem. Six items (e.g., "On the whole, I am satisfied with myself") were adopted from the Rosenberg self-esteem scale [61]. Prior research [61] showed the longer version of this scale to be reliable and valid.

\section{Results}

As shown in Table 2, maturity was positively associated with psychological well-being dimensions, as well as optimism and social support. Maturity was negatively associated with loneliness and positively associated with longer measures of satisfaction with life and self-esteem.

\section{Discussion}

The results again support the notion that viewing oneself as mature correlates with self-reported well-being. We next planned to conduct a cross-national study to examine whether the results are unique to U.S. participants (although positive associations were found for participants from various countries in Study 2). Prior to conducting a cross-national study we first examined the validity of single-item measures for physical and subjective well-being in Study 4.

\section{STUDY 4}

The purpose of Study 4 was to examine the associations between maturity and well-being and provide initial validity for single-item measures of dimensions of well-being. We expect to observe initial validity evidence for the single-item measures. Additionally, as we hypothesized across all of the studies: we expected maturity to be positively associated with indicators of well-being.

\section{Participants and Procedure}

Participants included undergraduate students at Texas A\&M University-Commerce participating for course or extra credit (see Table 1 for participant characteristics; approved by Texas A\&M University-Commerce IRB \#1472). Participants completed single-item well-being measures, longer measures of well-being, and the same measure of maturity used in Studies 1-3. Measures were presented in a randomized order, followed by a self-report of participants' height and weight (to calculate body mass index as an indicator of physical health). Unless noted otherwise, measures used a 7-point Likert-type scale, from $1=$ strongly disagree to $7=$ strongly agree .

\section{Measures}

\section{Maturity}

Maturity was assessed with the same measure utilized in Study $1(\alpha=.91 ; \mathrm{M}=5.72, \mathrm{SD}=1.25)$.

\section{Physical well-being}

We adopted a single item ("I am in good physical health") from a previously published measure [62]. To assess the validity of the single item we also included the BBC physical well-being subscale (identical to Study 1), and assessed participants' height and weight to calculate body mass index [63].

\section{Subjective well-being}

Six items were adapted from or constructed to represent the six dimensions of Ryff and Keyes' [22] measure of well-being, including autonomy ("I make choices by myself without the help of others"), environmental mastery ("I have been able to create a lifestyle for myself that is much to my liking"), personal growth ("I seek out new experiences to grow as a person"), positive relations with others ("I have warm and satisfying relationships with others"), purpose in life ("I feel I have purpose in life"), and self-acceptance ("In general, I feel confident and positive about myself"). To assess the convergent validity of these single-item measures, we also included the full 42 -item well-being measure (identical to Study 3 ). 


\section{Results}

As a preliminary analysis, we first examined the correlations between the single items and longer measures. The single-item physical well-being was positively correlated with the BBC physical well-being subscale $(\mathrm{r}=.44, \mathrm{p}<.001)$ and negatively related to participants' body mass index $(r=-.29, \mathrm{p}<.001)$. The single items representing dimensions of Ryff and Keyes' [22] well-being were also positive and significantly related to the longer measures: autonomy $(r=.39$, $\mathrm{p}<.001)$, personal growth $(\mathrm{r}=.38, \mathrm{p}<$ $.001)$, positive relations with others $(\mathrm{r}=$ $.59, \mathrm{p}<.001)$, purpose in life $(\mathrm{r}=.40, \mathrm{p}<$ $.001)$. The single items for environmental mastery and self-acceptance were either identical or similar to items in the longer measure. Therefore, we removed those items from the longer measures before conducting the correlations: environmental mastery $(\mathrm{r}=.46$, $\mathrm{p}<.001)$, self-acceptance $(\mathrm{r}=.54, \mathrm{p}<.001)$. Thus, initial validity was provided for each of the single-item indicators of well-being.

To examine the associations between maturity and well-being we conducted correlations between these variables. As shown in Table 2 , self-rated maturity was positively correlated with both the single-item indicators of well-being as well as the longer measures of well-being. Furthermore, maturity was negatively correlated with participants' body mass index suggesting greater physical well-being.

\section{Discussion}

The results of Study 4 showed initial validity for the single-item indicators of well-being. Furthermore, the measures showed good reliability ${ }^{1}$. Maturity was once again positively related to the well-being measures and showed a negative relationship with an objective measure of physical well-being. Having shown initial validation of the single-item measures, we included them in a cross-national study of the association between maturity and well-being in Study 5 .

\section{STUDY 5}

The purpose of Study 5 was to examine the associations between maturity and well-being in samples from five countries.

\section{Participants and Procedure}

Participants included undergraduate students at Texas A\&M University-Commerce in the U.S., undergraduate students at MacEwan University in Canada, individuals solicited through

\footnotetext{
${ }^{1}$ To examine test-retest reliability of the single-item measures of Ryff and Keyes' [22] A\&M University-Commerce students ( $\mathrm{N}=245,77.6 \%$ female, $1.3 \%$ other; Mage $=21.62, \mathrm{SD}=6.02)$ completed the items at the beginning of the fall and spring semesters (about four months apart). Autonomy (MT1 $=4.61, \mathrm{SDT} 1=1.38 ; \mathrm{MT} 2=4.88, \mathrm{SDT} 2=1.52 ; \mathrm{r}=.67, \mathrm{p}<.001)$, environmental mastery $(\mathrm{MT} 1=4.67, \mathrm{SDT} 1=1.39 ; \mathrm{MT} 2=4.93$, SDT2 $=1.42 ; \mathrm{r}=.67$, $\mathrm{p}<.001)$, personal growth $(\mathrm{MT} 1=5.46, \mathrm{SDT} 1=1.23$; MT2 $=5.55, \mathrm{SDT} 2=$ $1.26 ; \mathrm{r}=.57, \mathrm{p}<.001)$, positive relations $(\mathrm{MT} 1=5.31, \mathrm{SDT} 1=1.17$; $\mathrm{MT} 2=$ 5.68$, SDT2 $=1.26 ; \mathrm{r}=.48, \mathrm{p}<.001)$, purpose in life $(\mathrm{MT} 1=5.43, \mathrm{SDT} 1=$ $1.55 ; \mathrm{MT} 2=5.50$, SDT2 $=1.46 ; \mathrm{r}=.60, \mathrm{p}<.001)$, and self-acceptance $(\mathrm{MT} 1=$ $4.79, \mathrm{SDT} 1=1.56 ; \mathrm{MT} 2=5.02, \mathrm{SDT} 2=1.52 ; \mathrm{r}=.57, \mathrm{p}<.001)$ showed good test-retest reliability. As a comparison, Postmes et al. [64] found that the correlation between time points five weeks apart of a single-item measure of ingroup identification was .42 .
}

friendship networks in Brazil, undergraduate students at Vietnam National University in Vietnam, and students at Karnatak University in India (see Table 1 for participant characteristics; approved by Texas A\&M University-Commerce IRB \#1649). The surveys in the U.S., Canada, and India were administered in English. The survey in Brazil was administered in Portuguese and Vietnamese for participants in Vietnam (both were back translated). As part of a survey regarding a variety of topics (e.g., fandom, global citizenship), participants completed measures of maturity and well-being. All measures used a 7-point Likert-type scale, from $1=$ strongly disagree to $7=$ strongly agree.

\section{Measures}

Maturity was assessed with the same measure utilized in Study $1(\alpha=.81)$. Self-esteem and satisfaction with life were

the same measures used in Study 2. The single items used to assess physical well-being and dimensions of Ryff and Keyes' [22] well-being were the same as those shown to be valid and reliable in Study 4.

\section{Results}

To examine the associations between maturity and indicators of well-being we conducted zero-order correlations separate for each country sample. As shown in Table 3, maturity was positively related with self-esteem across all countries except Canada. Satisfaction was also positively correlated, again with Canada as the exception. Physical well-being showed significant correlations, however, only a marginally significant positive association was observed for the Brazilian sample. Ryff and Keyes' [22] dimensions of well-being showed a similar trend with positive correlations with minor exceptions (e.g., environmental mastery showed non-significant associations with maturity in the Brazil and India samples).

\section{Discussion}

Overall, the results suggest that the association between self-rated maturity and well-being is largely replicated in samples outside the U.S. However, for some associations the magnitude of the relationship was smaller than that found in the U.S. samples presented thus far.

\section{GENERAL DISCUSSION}

The purpose of the present research was to examine associations between maturity and well-being. We predicted, and found consistent evidence, that self-rated maturity is associated with a wide variety of indicators of well-being. Furthermore, after constructing, and testing validity and 
reliability of, single-item measures of dimensions of well-being, we found partial evidence of consistency of associations across culturally diverse samples. Together, the results provide further evidence of an association between maturity and well-being.

\section{Maturity and Well-Being}

Research concerning maturity is fraught with conceptualizations and operationalizations of the concept. Thus, it is difficult to compare research findings, such as the association with well-being, across studies. To overcome this issue, in the present research we used a short self-report measure of perceived maturity. Prior research [10] showed the measure loads onto the same factor with dimensions of previously suggested measures of maturity (e.g., psychosocial maturity, identity resolution). Given that prior research tends to assess only one or two indicators of well-being (typically in a single sample), in the present research we included various indicators of well-being and multiple culturally diverse samples. Supporting the results from prior research $[7,9]$, the results of the present study showed that maturity is positively related to various indicators of well-being. Well-being researchers typically conceptualize well-being as consisting of two dimensions: one being a positive evaluation of life the other a sense of purpose in life [1]. The results of the present study showed that maturity is associated with indicators representing both dimensions of well-being. Furthermore, maturity was additionally related to physical well-being, including an objective measure (BMI). The results also supported prior research [13, 17,20 ] showing an association between maturity and well-being in non-U.S. samples.

\section{Maturity in Healthcare Profession}

The present research holds a variety of implications for the healthcare profession. Maturity is often mentioned as a desired characteristic in potential students and employees [37-40]. Maturity is an important component for job performance such as collaboration on healthcare teams [31-33]. Furthermore, maturity appears related to medical professionals' well-being including reduced likelihood of burnout [41-45]. The present research indeed supports this prior research by showing consistent relationships between maturity and indicators of well-being. Individuals who are more mature may thrive in the healthcare professions due to reduced stress and better job performance.

Future researchers may assess perceived maturity of students and examine the construct as a predictor of school and clinical performance. A maturity assessment may also predict risk of employee burnout. Beyond healthcare professionals, assessments of maturity may predict patient compliance with medical advice.

\section{LIMITATIONS}

The results support prior research showing associations between well-being and maturity. However, there are limitations that prevent generalization of the results. First, although Study 5 included four non-U.S. samples, and the results showed a general trend, not all of the associations were identical across samples. This may be due to the measures themselves or actual patterns in those cultural spaces. Further sampling in additional countries is warranted given the present findings. A second limitation of the present study is that all of the studies are correlational in nature. As such, we cannot infer causal relations. While we argue in favor of a self-report, short, straightforward measure of maturity, a more subtle and longer measure may capture a greater variety of dimensions or implicit assessment of maturity. Despite these shortcomings, however, the replicability of the findings across samples and different measures of well-being allow us to be fairly confident in a strong association between viewing oneself as mature and feeling happy and well situated in one's life.

\section{CONCLUSION}

To conclude, we examined the association between perceived maturity and well-being across a variety of samples and indicators of well-being. The results across the studies point to a positive relationship between maturity and indicators of well-being. Furthermore, maturity was related to physical well-being and variables related to well-being (self-compassion, empathy, self-awareness). The results highlight the importance of maturity when assessing well-being.

\section{REFERENCES}

1. Ryan RM, Deci EL. On happiness and human potentials: a review of research on hedonic and eudaimonic well-being. Annu Rev Psychol. 2001;52(1):141-66.

2. Compton WC. Toward a tripartite factor structure of mental health: subjective well-being, personal growth, and religiosity. J Psychol. 2001 Sep;135(5):486-500.

3. Compton WC, Smith ML, Cornish KA, Qualls DL. Factor structure of mental health measures. J Pers Soc Psychol. 1996 Aug;71(2):406-13.

4. Keyes CL, Shmotkin D, Ryff CD. Optimizing well-being: the empirical encounter of two traditions. J Pers Soc Psychol. 2002 Jun;82(6):1007-22.

5. Doll EA. A genetic scale of social maturity. Am J Orthopsychiatry. 1935;5(2):180-90.

6. Tan AL, Kendis RJ, Fine JT, Porac J. A short measure of Eriksonian ego identity. J Pers Assess. 1977 Jun;41(3):279-84.

7. Greenberger E, Josselson R, Knerr C, Knerr B. The measurement and structure of psychosocial maturity. J Youth Adolesc. 1975 Jun;4(2):127-43.

8. Weinberger DA. (1991). Social-emotional adjustment in older children and adults: I. Psychometric properties of the Weinberger Adjustment Inventory. Unpublished manuscript. Case Western Reserve University, Cleveland, $\mathrm{OH}$.

9. Roberts SE, Côté JE. The identity issues inventory: identity state resolution in the prolonged transition to adulthood. J Adult Dev. 2014;21(4):225-38.

10. Reysen S, Plante CN. Fans, perceived maturity, and willingness to form a romantic relationship: application of a short maturity measure. Communication and Culture Online. 2017;8(1):154-73.

11. Josselson R, Greenberger E, McConochie D. (1975). On the validity of the psychosocial maturity inventory: Relationship to measures of personal well-being. Report No. 199. Baltimore, MD: Center for the Study of Social Organization of Schools, John Hopkins University.

12. Monahan KC, Steinberg L, Cauffman E, Mulvey EP. Trajectories of antisocial behavior and psychosocial maturity from adolescence to young adulthood. Dev Psychol. 2009 Nov;45(6):1654-68.

13. Wintre MG, Bowers CD. Predictors of persistence to graduation: extending a model and data on the transition to university model. Can J Behav Sci. 2007;39(3):220-34.

14. de Man AF, Harvey S, Ward SL, Benoît A. Ego-identity, self-esteem, and psychological stress in adolescents who attend school and work part-time. Individual Differences Res. 2008;6(4):245-52.

15. Galambos NL, Magill-Evans J, Darrah J. Psychosocial maturity in the transition to adulthood for people with and without motor disabilities. Rehabil Psychol. 2008;53(4):498-504. 
16. Sheldon KM, Kasser T. Getting older, getting better? Personal strivings and psychological maturity across the life span. Dev Psychol. 2001 Jul;37(4):491-501.

17. Neto F. Loneliness among Portuguese adolescents. Soc Behav Personal. 1992;20(1):15-22.

18. Carlozzi AF, Gaa JP, Liberman DB. Empathy and ego development. J Couns Psychol. 1983;30(1):113-6.

19. Crescentini C, Garzitto M, Paschetto A, Brambilla P, Fabbro F. Temperament and character effects on late adolescents' well-being and emotional-behavioural difficulties. PeerJ. 2018 Mar;6:e4484.

20. Joy M, Mathew A. Emotional maturity and general well-being of adolescents. IOSR J Pharm. 2018;8(5):1-6.

21. Bauer JJ, McAdams DP. Growth goals, maturity, and well-being. Dev Psychol. 2004 Jan;40(1):114-27.

22. Ryff CD, Keyes CL. The structure of psychological well-being revisited. J Pers Soc Psychol. 1995 Oct;69(4):719-27.

23. McCrae RR, Costa PT Jr. Psychological maturity and subjective well-being: toward a new synthesis. Dev Psychol. 1983;19(2):243-8.

24. Lee AG, Beaver HA, Boldt HC, Olson R, Oetting TA, Abramoff $\mathrm{M}$, et al. Teaching and assessing professionalism in ophthalmology residency training programs. Surv Ophthalmol. 2007 May-Jun;52(3):300-14.

25. O'Sullivan AJ, Toohey SM. Assessment of professionalism in undergraduate medical students. Med Teach. 2008;30(3):280-6.

26. Van De Camp K, Vernooij-Dassen MJ, Grol RP, Bottema BJ. How to conceptualize professionalism: a qualitative study. Med Teach. 2004 Dec;26(8):696-702.

27. Wagner P, Hendrich J, Moseley G, Hudson V. Defining medical professionalism: a qualitative study. Med Educ. 2007 Mar;41(3):288-94.

28. 28. Englander R, Cameron T, Ballard AJ, Dodge J, Bull J, Aschenbrener CA. Toward a common taxonomy of competency domains for the health professions and competencies for physicians. Acad Med. 2013 Aug;88(8):1088-94.

29. Grossman D, Jorda ML. Transitioning foreign-educated physicians to nurses: the New Americans in Nursing accelerated program. J Nurs Educ. 2008 Dec;47(12):544-51.

30. Perez-Bret E, Altisent R, Rocafort J. Definition of compassion in healthcare: a systematic literature review. Int J Palliat Nurs. 2016 Dec;22(12):599-606.

31. Lindeke LL, Sieckert AM. Nurse-physician workplace collaboration. Online J Issues Nurs. 2005 Jan;10(1):5.

32. Morley L, Cashell A. Collaboration in health care. J Med Imaging Radiat Sci. 2017 Jun;48(2):207-16.

33. Paradis E, Pipher M, Cartmill C, Rangel JC, Whitehead CR. Articulating the ideal: 50 years of interprofessional collaboration in Medical Education. Med Educ. 2017 Aug;51(8):861-72.

34. Sharma A, Schauer DP, Kelleher M, Kinnear B, Sall D, Warm E. USMLE step 2 CK: best predictor of multimodal performance in an internal medicine residency. J Grad Med Educ. 2019 Aug;11(4):412-9.

35. Nilsson MS, Pilhammar E. Professional approaches in clinical judgements among senior and junior doctors: implications for medical education. BMC Med Educ. 2009 May;9(1):25.

36. Moreau D, Goldgran-Toledano D, Alberti C, Jourdain M, Adrie C, Annane D, et al. Junior versus senior physicians for informing families of intensive care unit patients. Am J Respir Crit Care Med. 2004 Feb;169(4):512-7.

37. Cummings GG, Fraser K, Tarlier DS. Implementing advanced nurse practitioner roles in acute care: an evaluation of organizational change. J Nurs Adm. 2003
Mar;33(3):139-45.

38. Landsperger JS, Williams KJ, Hellervik SM, Chassan CB, Flemmons LN, Davidson SR, et al. Implementation of a medical intensive care unit acute-care nurse practitioner service. Hosp Pract (1995). 2011 Apr;39(2):32-9.

39. Lane IF. Professional competencies in health sciences education: from multiple intelligences to the clinic floor. Adv Health Sci Educ Theory Pract. 2010 Mar;15(1):129-46.

40. Salvatori P. Reliability and validity of admissions tools used to select students for the health professions. Adv Health Sci Educ Theory Pract. 2001;6(2):159-75.

41. Moreno-Milan B, Cano-Vindel A, Lopez-Dóriga P, Medrano LA, Breitbart W. Meaning of work and personal protective factors among palliative care professionals. Palliat Support Care. 2019 Aug;17(4):381-7.

42. Satterfield JM, Becerra C. Developmental challenges, stressors and coping strategies in medical residents: a qualitative analysis of support groups. Med Educ. 2010 Sep;44(9):908-16.

43. Shacklady J, Holmes E, Mason G, Davies I, Dornan T. Maturity and medical students' ease of transition into the clinical environment. Med Teach. 2009 Jul;31(7):621-6.

44. Peisah C, Latif E, Wilhelm K, Williams B. Secrets to psychological success: why older doctors might have lower psychological distress and burnout than younger doctors. Aging Ment Health. 2009 Mar;13(2):300-7.

45. Ramírez MR, Otero P, Blanco V, Ontaneda MP, Díaz $\mathrm{O}$, Vázquez FL. Prevalence and correlates of burnout in health professionals in Ecuador. Compr Psychiatry. 2018 Apr;82:73-83.

46. Kinderman P, Schwannauer M, Pontin E, Tai S. The development and validation of a general measure of well-being: the BBC well-being scale. Qual Life Res. 2011 Sep;20(7):1035-42.

47. Neff KD. Self-compassion, self-esteem, and well-being. Soc Personal Psychol Compass. 2011;5(1):1-12.

48. Morelli SA, Lieberman MD, Zaki J. The emerging study of positive empathy. Soc Personal Psychol Compass. 2015;9(2):57-68.

49. Richards KC, Campenni CE, Muse-Burke JL. Self-care and well-being in mental health professionals: the mediating effects of self-awareness and mindfulness. J Ment Health Couns. 2010;32(3):247-64.

50. Raes F, Pommier E, Neff KD, Van Gucht D. Construction and factorial validation of a short form of the Self-Compassion Scale. Clin Psychol Psychother. 2011 May-Jun;18(3):250-5.

51. Davis MH. Measuring individual differences in empathy: evidence for a multidimensional approach. J Pers Soc Psychol. 1983;44(1):113-26.

52. Govern JM, Marsch LA. Development and validation of the situational self-awareness scale. Conscious Cogn. 2001 Sep;10(3):366-78.

53. Antony MM, Bieling PJ, Cox BJ, Enns MW, Swinson RP. Psychometric properties of the 42 -item and 21-item versions of the depression anxiety stress scales in clinical groups and a community sample. Psychol Assess. 1998;10(2):176-81.

54. Lucas RE, Donnellan MB. Estimating the reliability of single-item life satisfaction measures: results from four national panel studies. Soc Indic Res. 2012 Feb;105(3):323-31.

55. Reysen S, Plante CN, Roberts SE, Gerbasi KC. "Coming out" as an anime fan: cosplayers in the anime fandom, fan disclosure, and well-being. The Phoenix Papers. 2018;4(1):1-9.

56. Robins RW, Hendin HM, Trzesniewski KH. Measuring global self-esteem: construct validation of a single-item measure and the Rosenberg self-esteem scale. Pers Soc Psychol Bull. 2001;27(2):151-61. 
57. Scheier MF, Carver CS. Optimism, coping, and health: assessment and implications of generalized outcome expectancies. Health Psychol. 1985;4(3):219-47.

58. Cyranowski JM, Zill N, Bode R, Butt Z, Kelly MA, Pilkonis PA, et al. Assessing social support, companionship, and distress: national institute of health (NIH) toolbox adult social relationship scales. Health Psychol. 2013 Mar;32(3):293-301.

59. Russell DW. UCLA Loneliness Scale (Version 3): reliability, validity, and factor structure. J Pers Assess. 1996 Feb;66(1):20-40.

60. Diener E, Emmons RA, Larsen RJ, Griffin S. The satisfaction with life scale. J Pers Assess. 1985 Feb;49(1):71-5.

61. Rosenberg M. Society and the adolescent self-image. Princeton University Press; 1965. https://doi. org/10.1515/9781400876136.

62. Snell WE Jr, Johnson G, Lloyd PJ, Hoover MW. The health orientation scale: A measure of psychological tendencies associated with health. Eur J Pers. 1991;5(2):169-83.

63. Flegal KM, Carroll MD, Kit BK, Ogden CL. Prevalence of obesity and trends in the distribution of body mass index among US adults, 1999-2010. JAMA. 2012 Feb;307(5):491-7.

64. Postmes T, Haslam SA, Jans L. A single-item measure of social identification: reliability, validity, and utility. Br J Soc Psychol. 2013 Dec;52(4):597-617.

65. Tavakol M, Dennick R. Making sense of Cronbach's alpha. Int J Med Educ. 2011 Jun;2:53-5.

66. Mukaka MM. Statistics corner: A guide to appropriate use of correlation coefficient in medical research. Malawi Med J. 2012 Sep;24(3):69-71.

67. Taylor R. Interpretation of the correlation coefficient: A basic review. J Diagn Med Sonogr. 1990;6(1):35-9. 